\title{
Effect of erythropoietin on level of circulating endothelial progenitor cells and outcome in patients after acute ischemic stroke
}

\author{
Hon-Kan Yip ${ }^{1,2^{*}}$, Tzu-Hsien Tsai ${ }^{1}$, Hung-Sheng Lin ${ }^{3}$, Shu-Fang Chen ${ }^{3}$, Cheuk-Kwan Sun ${ }^{2,4}$, Steve Leu ${ }^{1,2}$, \\ Chun-Man Yuen ${ }^{5}$, Teng-Yeow Tan ${ }^{3}$, Min-Yu Lan ${ }^{3}$, Chia-Wei Liou ${ }^{3}$, Cheng-Hsien Lư ${ }^{3}$, Wen-Neng Chang ${ }^{3+}$
}

\begin{abstract}
Introduction: Erythropoietin (EPO) enhances the circulating level of endothelial progenitor cells (EPCS), which has been reported to be associated with prognostic outcome in ischemic stroke (IS) patients. The aim of this study was to evaluate the time course of circulating EPC level and the impact of EPO therapy on EPC level and clinical outcome in patients after acute IS.

Methods: In total, 167 patients were prospectively randomized to receive either EPO therapy (group 1) (5,000 IU each time, subcutaneously) at $48 \mathrm{~h}$ and $72 \mathrm{~h}$ after acute $\mathrm{IS}$, or serve as placebo (group 2). The circulating level of EPCs (double-stained markers: CD31/CD34 $\left(E_{1}\right), \operatorname{CD} 62 E / C D 34\left(E_{2}\right)$ and KDR/CD34 $\left(E_{3}\right)$ ) was determined using flow cytometry at $48 \mathrm{~h}$ and on days 7 and 21 after IS. EPC level was also evaluated once in 60 healthy volunteers.

Results: Circulating EPC ( $E_{1}$ to $E_{3}$ ) level at $48 \mathrm{~h}$ after IS was remarkably higher in patients than in control subjects $(P<0.02)$. At $48 \mathrm{~h}$ and on Day 7 after IS, EPC $\left(E_{1}\right.$ to $\left.E_{3}\right)$ level did not differ between groups 1 and 2 (all $P>0.1$ ). However, by Day 21, EPC ( $E_{1}$ to $\left.E_{3}\right)$ level was significantly higher in group 1 than in group 2 (all $P<0.03$ ). Additionally, 90-day recurrent stroke rate was notably lower in group 1 compared with group $2(P=0.022)$. Multivariate analysis demonstrated that EPO therapy (95\% confidence interval $(C \mathrm{Cl}), 0.153$ to $0.730 ; P=0.006)$ and EPC (E3) (95\% Cl, 0.341 to 0.997; $P=0.049)$ levels were significantly and independently predictive of a reduced 90day major adverse neurological event (MANE) (defined as recurrent stroke, National Institutes of Health Stroke scale $\geq 8$, or death).
\end{abstract}

Conclusions: EPO therapy significantly improved circulating EPC level and 90-day MANE.

Trial registration number: ISRCTN: ISRCTN96340690

\section{Introduction}

Stroke, a growing epidemic, remains a leading cause of mortality and disability worldwide [1-3]. Surprisingly, while the epidemiology, etiologies, mechanisms, classification, and prognostic outcomes of ischemic stroke (IS) have been widely investigated for several decades, a safe and effective treatment strategy for patients after acute IS has not been fully developed [4-8].

\footnotetext{
* Correspondence: han.gung@msa.hinet.net

+ Contributed equally

'Division of Cardiology, Department of Internal Medicine, Chang Gung Memorial Hospital - Kaohsiung Medical Center, Chang Gung University College of Medicine, 123 Ta-Pei Road, Niaosong District, Kaohsiung City, 833, Taiwan

Full list of author information is available at the end of the article
}

Recently, thrombolysis using tissue plasminogen activator (tPA), a more aggressive management strategy, has been shown to be effective for some acute IS patients early after the onset of symptoms $[9,10]$. However, tPA use is hampered by many limitations in daily clinical practice [10-13]. In addition to its narrow indication for only a small number of patients, tPA therapy has been reported to have a relatively high incidence of intracranial bleeding complications $[13,14]$. The majority of acute IS patients, therefore, are still left without any specific treatment. Hence, finding a safe and effective therapeutic regimen for patients following acute IS, especially those unsuitable for thrombolytic therapy, is of utmost importance for physicians.

\section{() Biomed Central}


Erythropoietin (EPO) was originally used for treating anemic patients of various etiologies, especially for patients with uremia. Interestingly, in addition to its role in normalizing erythropoiesis, EPO has been clearly shown to exert a myocardial protective effect against ischemia-related damage [15-17]. In contrast, the neuroprotective effect of EPO after acute IS is not welldocumented and the results are inconsistent [18-20]. The mechanisms underlying the anti-ischemic action of EPO have been proposed to involve anti-apoptotic processes $[15,16]$, neovascularization, mobilization of endothelial progenitor cells (EPCs), and angiogenesis [21-23]. An increase in circulating levels of EPCs in patients after acute IS has been demonstrated to be strongly associated with favorable clinical outcomes in our recent study [24]. Accordingly, we proposed that other than its role in protecting myocardium against ischemic insult, EPO therapy may enhance the circulating EPC level and improve neurological function and clinical outcome in patients after acute IS.

\section{Materials and methods Study design}

This clinical trial was approved by the Institutional Review Committee on Human Research in Chang Gung Memorial Hospital (No 96-1381A) in 2007 and conducted at Kaohsiung Chang Gung Memorial Hospital.

This was a prospective, randomized, and placebo-controlled trial. The primary objective was to evaluate the safety and efficacy of two consecutive doses of EPO (Epoetin beta, Roche, Basel, Switzerland) (5,000 IU each time, subcutaneously) administered at $48 \mathrm{~h}$ and $72 \mathrm{~h}$ after acute IS in improving the 90-day combined endpoint of recurrent stroke or death. The secondary objective of this study was to establish the time course of circulating levels of EPCs in patients after acute IS and the ability of two doses of EPO in enhancing circulating EPC level. In addition, this study's intent was to assess the impact of EPO therapy on improving the combined adverse neurological event (MANE) (defined as recurrent stroke, National Institutes of Health Stroke Scale (NIHSS) $\geq 8$, or death). The definition of the MANE was based on our recent reports $[8,24]$. Instead of EPO, the placebo-control subjects received a $1 \mathrm{~mL}$ normal saline subcutaneous injection at $48 \mathrm{~h}$ and $72 \mathrm{~h}$ after acute IS. Additionally, a neurologist blinded to the treatment allocation assessed the outcomes. The medication (trial agent) was given by a clinician blinded to the patients' clinical condition. Patients who had a history of allergy to EPO, hematological disorders including myeloproliferative disorder, leukemia, thrombocythemia, polycythemia, past history of deep vein thrombosis, abnormal elevation of hemoglobin (male $>14.5 \mathrm{gm} / \mathrm{dL}$; female $>13.5 \mathrm{gm} / \mathrm{dL}$ ) were excluded from this trial.

\section{Calculation of sample size for specific objective}

The study included consecutively admitted acute IS patients at a single facility between October 2008 and March 2010. For the primary objective of the study, an estimated sample size of 106 study patients in each group was based on the effective size with an $\alpha=0.05$, a power of $80 \%$, an anticipation of a combined end point of $14.0 \%$ in placebo control vs. $4.0 \%$ with EPO therapy. For the secondary objective of this study, an estimated sample size of 93 study patients in each group was based on the effective size with an $\alpha=0.05$, a power of $80 \%$, an average difference in circulating level of EPCs between the EPO therapy and placebo-control group of $0.32 \%$, and a standard deviation of circulating level of EPCs in EPO therapy was 0.7\%. A 20\% rate of protocol violations and incomplete follow-up was assumed. The calculation of sample size for specific objective was based on our recent report [24].

\section{Definition and exclusion criteria}

Stroke was defined as sudden onset of loss of global or focal cerebral function persisting for more than $24 \mathrm{~h}$. Patients of any age with acute IS were eligible. Inclusion criteria included a scoring of $>2$ on the NIHSS (scores up to 8 indicate moderate neurological status disability) and a time window of $\leq 48 \mathrm{~h}$ from onset of symptoms to blood sampling (at $48 \mathrm{~h}$ after IS) and study drug administration (time to treatment just after blood sampling). Patients with a history of the following were excluded from the study: intracranial hemorrhage, surgery or trauma within the preceding three months, abnormal liver function, hematology disorders, renal insufficiency (serum creatinine $>1.5 \mathrm{mg} / \mathrm{dL}$ ), malignancy, febrile disorders, acute or chronic inflammatory disease at study entry, liver cirrhosis, atrial fibrillation, congestive heart failure, contraindications for Magnetic Resonance Imaging (MRI) examination, no evidence of acute IS by MRI study, myeloproliferative disorder, antibodies or allergies to EPO, pregnancy, tPA therapy for acute IS, or a hemoglobin level $>15.0 \mathrm{gm} / \mathrm{dL}$.

An overview of the study protocol of this clinical trial is shown in Figure 1. From October 2008 through March 2010, consecutive patients with acute IS were enrolled by the responsible neurologists at the institute. Patients were randomly assigned to different treatment groups after giving informed consent. Over a period of 18 months, 230 consecutive patients with IS occurring less than $48 \mathrm{~h}$ prior to blood sampling were recruited.

Twenty-five (23.1\%) of the 108 EPO-treated (group 1) patients were excluded due to unavailable MRI data (two patients), paroxysmal atrial fibrillation (four patients), refused EPO therapy (fifteen patients), or incomplete follow-up (four patients) that occurred later after the IS. Therefore, the remaining 83 patients 


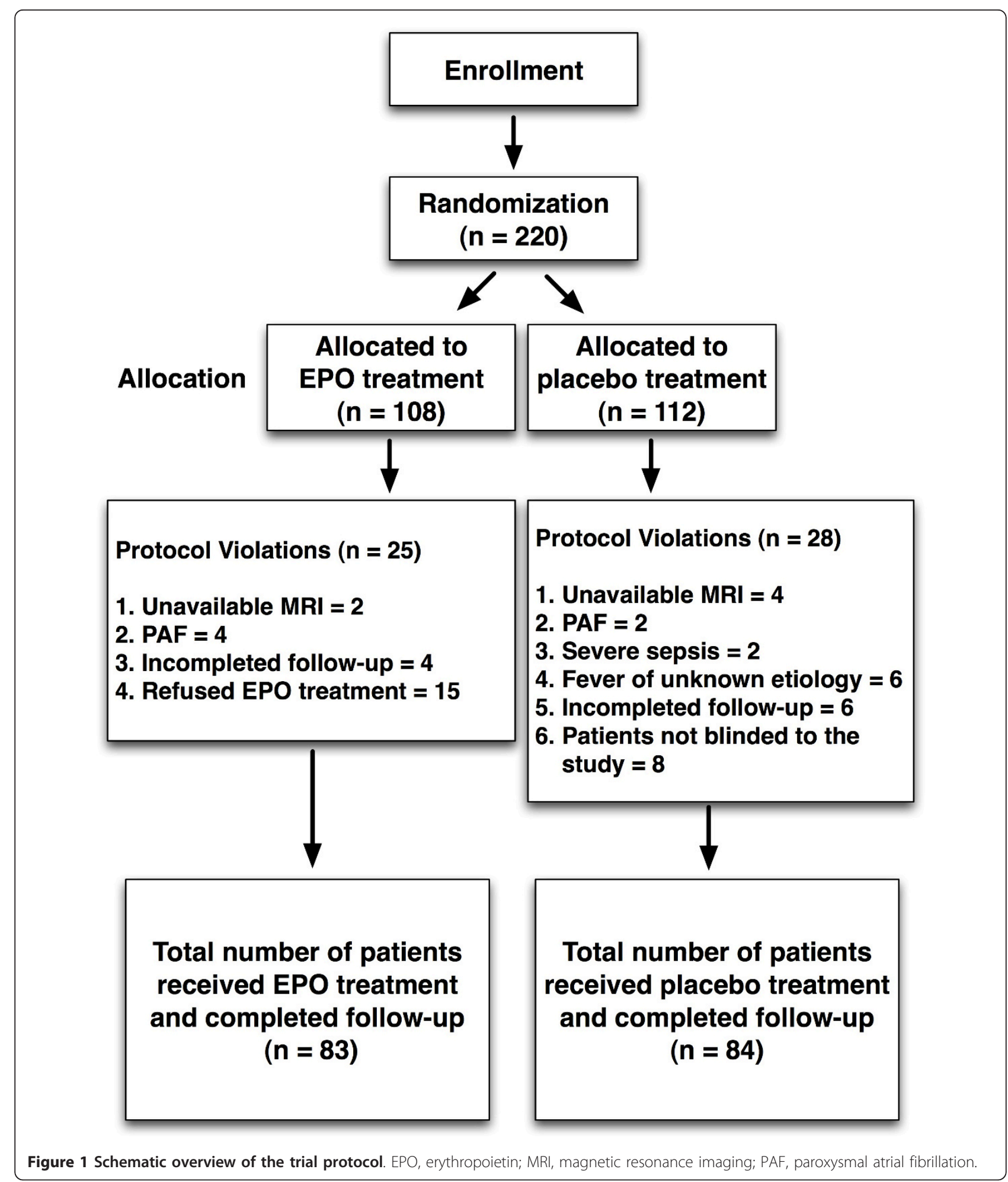

constituted the EPO therapy group (group 1). Twenty (17.9\%) of the 112 patients in the placebo control group (group 2) were excluded due to unavailable MRI data (four patients), paroxysmal atrial fibrillation (two patients), fever and sepsis (two patients), fever of unknown etiology (six patients), or incomplete followup (six patients) that occurred later after the IS. Additionally, eight patients $(7.1 \%)$ who insisted on knowing the type of therapeutic drug after enrollment were also excluded even though their blood samples were 
collected. Therefore, the remaining 84 patients constituted group 2 (placebo control) of this study.

Sixty age- and gender-matched healthy volunteers were also studied for circulating level of EPCs. Informed consent was obtained from all study subjects.

\section{Neurological assessment}

Evaluation of the physical function and degree of neurological impairment in the stroke patients was based on the National Institutes of Health Stroke Scale (NIHSS) [25] during the acute (at $48 \mathrm{~h}$ ), convalescent (on Day 21 ), and chronic (Day 90) phases of stroke by neurologists blinded to the treatment allocation (double-blind study). Moderate neurological impairment (that is, neurological sequelae that requires partial support in daily activities) was defined as a score of $\geq 8$ on NIHSS, a modified criteria reported previously [4]. In addition to NIHSS, assessments only during admission included functional measures, Barthel Index [26] [range from 100 (no deficit) to 0 (complete dependence or death)], and modified Rankin Scale score [27] (range from 0 (no residual symptoms) to 6 (indicating death)).

\section{Imaging studies and laboratory investigations}

In addition to full clinical assessment, other examinations performed also included chest X-ray film, routine brain computed tomography, duplex scanning of the carotid arteries, and routine cardiac analysis by 12 -lead electrocardiogram and echocardiography. Moreover, white blood cell (WBC) count, red blood cell (RBC) count, hemoglobin, and biochemical data were acquired at $48 \mathrm{~h}$ and on days 7 and 21 after acute IS.

The radiological diagnosis of acute IS included brain computed tomography showing a new finding of low attenuation density in focal or diffuse brain area; or MRI examination showing area(s) of high intensity (bright spots) on diffusion weighted image (DWI) MRI or lower intensity on apparent diffusion coefficient (ADC) value MRI.

\section{Blood sampling and assessment of circulating EPC level by flow cytometry}

Blood samples were obtained at $48 \mathrm{~h}$ (acute phase) and on days 7 (recovery phase) and 21 (convalescent phase) after IS at 9.00 a.m. for assessment of the serial changes in circulating level of EPCs in IS patients. Blood samples were also obtained in control subjects who participated in a health screening program in our Health Clinic once at 9.00 a.m.

Ten milliliters of blood was drawn from the antecubital vein into a vacutainer containing $3.8 \%$ buffered sodium heparin. Mononuclear cells (MNCs) were then isolated by density-gradient centrifugation of Ficoll 400 (Ficoll-Plaque $^{\mathrm{TM}}$ plus, Amersham Biosciences, Uppsala,
Sweden), based on our recent report [24]. The MNCs were washed twice with phosphate buffered saline (PBS) and centrifuged before incubation with $1 \mathrm{~mL}$ blocking buffer for 30 minutes at $4^{\circ} \mathrm{C}$. Cell variability of $>95.0 \%$ was noted in each group.

A flow cytometric method for identification of EPCs derived from peripheral blood has been reported in our recent studies and also those by others $[24,28,29]$. Briefly, the isolated MNCs $\left(4 \times 10^{5}\right)$ were incubated for 30 minutes at $4^{\circ} \mathrm{C}$ in a dark room with monoclonal antibodies against kinase insert domain-conjugating receptor (KDR) (Sigma, St. Louis, MO, USA), the fluorescein isothiocyanate (FITC)-conjugated CD34 and the phycoerythrin (PE)-conjugated CD31, and CD62E (Becton Dickinson, San Jose, CA, USA) to determine the EPC surface markers of CD31/CD34 $\left(\mathrm{E}_{1}\right)$, CD62E/CD34 $\left(\mathrm{E}_{2}\right)$, and $\mathrm{KDR} / \mathrm{CD} 34\left(\mathrm{E}_{3}\right)$, The control ligand (IgG-PE conjugate) was used to detect any nonspecific association and define a threshold for glycoprotein binding. For analysis of KDR, the MNCs were further incubated with PEconjugated anti-mouse antibody made in goat. After staining, the MNCs were fixed in $1 \%$ of paraformaldehyde. Quantitative two-colored flow cytometric analysis was performed using a fluorescence-activated cell sorter (FACSCalibur ${ }^{\mathrm{TM}}$ system; Beckmen Coulter, Brea, CA, USA). Each analysis included 30,000 cells per sample. The assays for EPCs $\left(E_{1 \text { to } 3}\right)$ in each sample were performed in duplicate, with the mean level reported.

Intra-assay variability based on repeated measurement of the same blood sample was low with a mean coefficient of variance being $3.9 \%$ and $3.6 \%$ in stroke patients and in normal subjects, respectively.

\section{Medications}

Aspirin was the first choice for acute stroke patients unless they were allergic or intolerant to aspirin, including a history of peptic ulcer or upper gastro-intestinal tract bleeding during aspirin therapy. Clopidogrel was used in patients intolerant to aspirin therapy. Other commonly used drugs included statins, angiotensin converting enzyme inhibitors (ACEIs)/angiotensin II type I receptor blockers (ARB), diuretics, calcium channel blocking agents, and beta blockers.

\section{Statistical analysis}

Chi-square test or Fischer's exact test was used where appropriate. Comparisons of means were performed using Student $t$-test. Continuous variables at three time points in the three groups were compared using repeated measure of ANOVA followed by Tukey multiple comparison procedure. Multivariate logistic regression analysis was utilized for identifying the independent predictors of EPCs level and prognostic outcomes. Statistical analysis was performed using SAS statistical 
software for Windows version 8.2 (SAS institute, Cary, NC, USA). A value of $P<0.05$ was considered statistically significant.

\section{Results}

Baseline characteristics and laboratory findings of study patients and healthy controls

Table 1 displays the baseline demographic and laboratory findings of both IS patients (that is, group $1=$ EPO-treated group, group 2 = placebo control) and healthy controls. There were no significant differences in terms of age, gender, body mass index, diastolic blood pressure (DBP), total cholesterol level, low-density lipoprotein (LDL), serum creatinine level, RBC count, hemoglobin, or hematocrit level between three groups. However, high-density lipoprotein (HDL) was notably lower in IS patients than in healthy controls. In contrast, WBC count and systolic blood pressure (SBP) were remarkably higher in groups 1 and 2 of IS patients compared with the control subjects. Moreover, the level of circulating EPCs ( $E_{1}$ to 3 ) was substantially higher in both groups of IS patients than in healthy controls.

The risk factors of cerebrovascular disease, incidence of previous stroke documented by history or MRI, old myocardial infarction, or hemoglobin $\mathrm{A}_{1 \mathrm{C}}\left(\mathrm{HbA}_{1 \mathrm{C}}\right)$ did not differ between group 1 and group 2 patients.

Table 1 Comparison of baseline characteristics and laboratory findings among three groups

\begin{tabular}{|c|c|c|c|c|}
\hline Variables & Group $1(n=83) \dagger$ & Group $2(n=84) \dagger$ & Healthy Control $(n=60)$ & $P$-value* \\
\hline$\overline{\text { Age }(y)(\text { mean } \pm S D),}$ & $63.7 \pm 11.4$ & $67.0 \pm 11.1$ & $64.1 \pm 6.0$ & 0.078 \\
\hline Male, \% (n) & $65.1 \%(54)$ & $66.7 \%(56)$ & $65.0 \%(39)$ & 0.969 \\
\hline Hypertension, \% (n) & $63.9 \%(53)$ & $73.8 \%(62)$ & - & 0.165 \\
\hline Diabetes mellitus, \% (n) & $37.4 \%(31)$ & $32.1 \%(27)$ & - & 0.480 \\
\hline Current smoking, \% (n) & $36.1 \%(30)$ & $273.4 \%(23)$ & - & 0.224 \\
\hline Previous stroke by history, \% (n) & $24.1 \%(20)$ & $21.4 \%(18)$ & - & 0.681 \\
\hline Previous stroke by MRI, \% (n) & $62.7 \%(52)$ & $57.1 \%(48)$ & - & 0.468 \\
\hline Old myocardial infarction, \% (n) & $8.4 \%(7)$ & $6.0 \%(5)$ & - & 0.549 \\
\hline RBC count $\left(\times 10^{6} / \mu \mathrm{L}\right)$ & $4.74 \pm 0.67$ & $4.68 \pm 0.68$ & $4.81 \pm 0.64$ & 0.561 \\
\hline Hemoglobin (g/dL) & $14.0 \pm 2.0$ & $14.1 \pm 1.8$ & $14.05 \pm 1.56$ & 0.963 \\
\hline Hematocrit (\%) & $41.3 \pm 5.9$ & $41.4 \pm 6.0$ & $40.9 \pm 6.1$ & 0.877 \\
\hline WBC count $\left(\times 10^{3} / \mu \mathrm{L}\right)$ & $7.82 \pm 2.38^{a}$ & $7.83 \pm 2.37^{\mathrm{a}}$ & $5.91 \pm 1.84^{\mathrm{b}}$ & $<0.0001$ \\
\hline \multicolumn{5}{|l|}{ Circulating level of EPCs at $48 \mathrm{~h}$} \\
\hline CD31/CD34 (\%) & $1.65 \pm 0.91^{\mathrm{a}}$ & $1.75 \pm 1.03^{\mathrm{a}}$ & $1.13 \pm 0.74^{b}$ & 0.0003 \\
\hline CD62E/CD34 (\%) & $1.21 \pm 0.86^{\mathrm{a}}$ & $1.16 \pm 0.76^{\mathrm{a}}$ & $0.93 \pm 0.83^{b}$ & 0.025 \\
\hline KDR/CD34 (\%) & $1.34 \pm 0.77^{\mathrm{a}}$ & $1.37 \pm 0.89^{\mathrm{a}}$ & $1.03 \pm 0.79^{b}$ & 0.03 \\
\hline Total cholesterol level (mg/dL) & $186.6 \pm 41.2$ & $190.1 \pm 42.7$ & $193.2 \pm 36.4$ & 0.621 \\
\hline $\mathrm{HDL}(\mathrm{mg} / \mathrm{dL})$ & $44.6 \pm 10.8^{\mathrm{a}}$ & $49.2 \pm 17.3^{\mathrm{a}}$ & $53.8 \pm 14.8^{b}$ & 0.001 \\
\hline $\mathrm{LDL}(\mathrm{mg} / \mathrm{dL})$ & $116.2 \pm 35.7$ & $115.2 \pm 39.4$ & $117.2 \pm 30.9$ & 0.949 \\
\hline Creatinine $(\mathrm{mg} / \mathrm{dL})$ & $1.00 \pm 0.38$ & $1.02 \pm 0.43$ & $1.01 \pm 0.24$ & 0.915 \\
\hline BMI $\left(\mathrm{kg} / \mathrm{m}^{2}\right)$ & $25.1 \pm 3.5$ & $24.2 \pm 3.9$ & $24.7 \pm 3.1$ & 0.225 \\
\hline $\mathrm{HbA}_{1 \mathrm{c}}$ level, \% & $6.73 \pm 1.85$ & $6.96 \pm 1.88$ & - & 0.468 \\
\hline $\mathrm{SBP}(\mathrm{mm} \mathrm{Hg})$ & $144 \pm 20^{\mathrm{a}}$ & $143 \pm 21^{a}$ & $136 \pm 18^{b}$ & 0.031 \\
\hline $\mathrm{DBP}(\mathrm{mm} \mathrm{Hg})$ & $83 \pm 12$ & $84 \pm 11$ & $85 \pm 11$ & 0.231 \\
\hline Significant ECCA stenosis, \% (n) & $24.1 \%(20)$ & $17.9 \% \%(15)$ & - & 0.322 \\
\hline Statin therapy & $43.4 \%(36)$ & $45.2 \%(38)$ & - & 0.808 \\
\hline ACEI/ARB therapy & $39.8 \%(33)$ & $38.1 \%(32)$ & - & 0.826 \\
\hline \multicolumn{5}{|l|}{ EPO therapy-related adverse events } \\
\hline Allergy & $0 \%(0)$ & $0 \%(0)$ & & - \\
\hline Polycythemia & $0 \%(0)$ & $0 \%(0)$ & & - \\
\hline Thrombosis event & $0 \%(0)$ & $0 \%(0)$ & & - \\
\hline
\end{tabular}

*: by Chi-square test or Fisher's exact test for categorical data; by t-test or one-way ANOVA for continuous data.

Letters $\left({ }^{a}, b\right)$ indicate significant difference (at 0.05 level) by Tukey multiple comparison procedure.

t: group 1, with EPO treatment; group 2, without EPO treatment.

Data are expressed as mean \pm SD or $\%$ (No.) of patients.

ACEI/ARB, angiotensin converting enzyme inhibitor/angiotensin II type I receptor blocker; BMI, body mass index; DBP, diastolic blood pressure; ECCA, extra-cranial carotid artery; EPC, endothelial progenitor cell; EPO, erythropoietin; $\mathrm{HbA}_{1 C}$, hemoglobin $\mathrm{A}_{1}$; $\mathrm{HDL}$, high-density lipoprotein; LDL, low-density lipoprotein; MRI, magnetic resonance imaging; SBP, systolic blood pressure; RBC, red blood cell; WBC, white blood cell. 
Additionally, the incidence of significant extra-cranial carotid artery (ECCA) stenosis (defined as $\geq 50 \%$ stenosis by carotid Doppler measurement) and the status of both statin and ACEI/ARB treatment did not significantly differ between the two groups. Importantly, no side effect of EPO therapy was recorded. This finding indicates that EPO therapy with the regimen of two consecutive dosages of 5,000 IU per patients is likely to be safe.

\section{Laboratory findings, circulating level of EPCs at three time points, neurological status, and clinical outcome after acute IS}

Table 2 shows that there was also no significant difference between the circulating levels of EPCs $\left(E_{1}\right.$ to $\left.E_{3}\right)$ at $48 \mathrm{~h}$ and on Day 7 between both groups of patients. Moreover, the RBC and WBC counts, hemoglobin, and hematocrit on Day 21 were similar among these patients. However, by Day 21, the circulating level of EPCs $\left(E_{1}\right.$ to $\left.E_{3}\right)$ was substantially higher in group 1 than in group 2 .

The scores of NIHSS, Barthel Index, and modified Ranking Scale score upon presentation (at $48 \mathrm{~h}$ after acute IS) did not differ between group 1 and group 2 (Table 3). Additionally, the mean NIHSS score on Day 90 did not differ between group 1 and group 2. However, the incidence of a NIHSS score $\geq 8$ on Day 90 was notably lower in group 1 than in group 2 . Furthermore, although the 90-day mortality was similar between the two groups, the incidence of recurrent stroke during a 90-day follow-up was notably lower in group 1 than in group 2. Besides, the incidence of 90-day major adverse neurological event (that is, MANE) was significantly reduced in group 1 compared with group 2 .

\section{Correlation between three individualized neurological assessment scales upon presentation and the circulating level of EPCs}

The Spearman rank correlation analysis did not identify significant correlation of circulating level of EPCs $\left(\mathrm{E}_{2}\right)$ to either modified Ranking Scale score or to Barthel Index at $48 \mathrm{~h}$ after acute IS (Figure 2). On the other hand, a significant negative correlation was noted between the circulating level of EPCs $\left(E_{1}\right.$ and $\left.E_{3}\right)$ and both modified Ranking Scale and Barthel Index at $48 \mathrm{~h}$ after acute IS. Besides, a significant negative correlation also was noted between the circulating level of EPCs $\left(\mathrm{E}_{1}\right.$ to $\left.E_{3}\right)$ and NIHSS at $48 \mathrm{~h}$ after acute IS.

\section{Time course of circulating level of EPCs}

The circulating level of EPCs $\left(\mathrm{E}_{1}\right.$ to $\left.\mathrm{E}_{3}\right)$ did not significantly alter at the chosen time points $(48 \mathrm{~h}$, on days 7 and 21) after acute IS in group 2 patients (Table 4). Consistently, the circulating level of EPCs did not significantly change between at $48 \mathrm{~h}$ and on Day 7 after acute IS in group 1 patients. However, the circulating level of EPC $\left(E_{1}\right.$ to $\left.E_{3}\right)$ was substantially increased on Day 21 compared with that at $48 \mathrm{~h}$ and on Day 7 after acute IS in group 1. These findings indicate that the effect of EPO therapy on boosting circulating EPC level was gradually increased after one week and up to a significantly higher level on Day 21 after acute IS.

Table 2 Laboratory findings and circulating level of EPCs between IS patients with and without EPO treatment

\begin{tabular}{|c|c|c|c|}
\hline Variables & Group $1+(n=83)$ & Group $2+(n=84)$ & $P$-value* \\
\hline \multicolumn{4}{|l|}{ Circulating level of EPCs at $48 \mathrm{~h}$} \\
\hline CD31/CD34 (\%) & $1.65 \pm 0.91$ & $1.75 \pm 1.03$ & 0.530 \\
\hline CD62E/CD34 (\%) & $1.21 \pm 0.86$ & $1.16 \pm 0.76$ & 0.704 \\
\hline KDR/CD34 (\%) & $1.34 \pm 0.76$ & $1.37 \pm 0.89$ & 0.791 \\
\hline \multicolumn{4}{|l|}{ Circulating level of EPCs on day 7} \\
\hline CD31/CD34 (\%) & $1.52 \pm 1.06$ & $1.48 \pm 0.89$ & 0.801 \\
\hline CD62E/CD34 (\%) & $1.11 \pm 0.76$ & $1.14 \pm 0.75$ & 0.855 \\
\hline KDR/CD34 (\%) & $1.16 \pm 0.70$ & $1.24 \pm 0.80$ & 0.523 \\
\hline \multicolumn{4}{|l|}{ Circulating level of EPCs on day 21} \\
\hline CD31/CD34 (\%) & $2.28 \pm 1.48$ & $1.64 \pm 0.79$ & 0.002 \\
\hline CD62E/CD34 (\%) & $1.50 \pm 1.13$ & $1.14 \pm 0.72$ & 0.030 \\
\hline KDR/CD34 (\%) & $1.81 \pm 1.25$ & $1.22 \pm 0.71$ & 0.001 \\
\hline RBC count $\left(\times 10^{6} / \mathrm{mL}\right)$ on day 21 & $4.56 \pm 0.73$ & $4.62 \pm 1.16$ & 0.719 \\
\hline Hemoglobin (g/dL) on day 21 & $13.7 \pm 1.9$ & $13.8 \pm 3.3$ & 0.746 \\
\hline Hematocrit (\%) on day 21 & $41.0 \pm 5.4$ & $39.9 \pm 6.4$ & 0.309 \\
\hline WBC count $\left(\times 10^{3} / \mathrm{mL}\right)$ on day 21 & $7.68 \pm 6.30$ & $7.27 \pm 2.47$ & 0.645 \\
\hline
\end{tabular}

*: by t-test.

t: group 1 = with EPO treatment; group 2 = without EPO treatment.

$\mathrm{EPC}=$ endothelial progenitor cell; $\mathrm{EPO}=$ erythropoietin; $\mathrm{RBC}=$ red blood cell; $\mathrm{WBC}=$ white blood cell. 
Table 3 Comparisons of neurological status and clinical outcome between IS patients with and without EPO treatment

\begin{tabular}{|c|c|c|c|}
\hline Variables & Group $1+(n=83)$ & Group $2+(n=84)$ & $P$-value* \\
\hline NIHSS at $48 \mathrm{~h}$ & $6.78 \pm 4.60$ & $7.35 \pm 7.55$ & 0.562 \\
\hline Modified Rankin Scale score at $48 \mathrm{~h}$ & $3.23 \pm 1.38$ & $2.89 \pm 1.62$ & 0.152 \\
\hline Barthel Index at $48 \mathrm{~h}$ & $55.7 \pm 30.5$ & $59.5 \pm 36.0$ & 0.467 \\
\hline NIHSS on day 90 & $4.27 \pm 5.39$ & $5.49 \pm 7.77$ & 0.239 \\
\hline Recurrent stroke, \% (n) & $0 \%(0)$ & $9.5 \%(8)$ & 0.007 \\
\hline 90-day mortality, \% (n) & $2.4 \%(2)$ & $1.2 \%(1)$ & 0.621 \\
\hline Primary end point, $\%(n) \neq$ & $2.4 \%(2)$ & $10.7 \%(9)$ & 0.057 \\
\hline $\mathrm{NIHSS} \geq 8.0$ & $14.5 \%(12)$ & $29.8 \%(25)$ & 0.017 \\
\hline Combined MANE, \% (n) & $16.9 \%(14)$ & $36.9 \%(31)$ & 0.004 \\
\hline
\end{tabular}

*: by Chi-square test or Fisher's exact test for categorical data; by $t$-test for continuous data.

t: group 1 = with EPO treatment; group 2 = without EPO treatment.

\#: defined as 90-day combined recurrent stroke or death.

ף: MANE = major adverse neurological event (defined as NIHSS $\geq 8$, recurrent stroke or death on Day 90 after acute IS).

IS, ischemic stroke; NIHSS, national institutes of health stroke scale.

Univariate and multivariate analyses of predictors for 90-day MANE

Univariate analysis of enrollment variables in Tables 1 and 3 demonstrated that serum levels of total cholesterol and LDL were significantly associated with 90-day MANE (Table 5). On the other hand, EPO therapy, increase in circulating level of EPC $\left(\mathrm{E}_{3}\right)$ at $48 \mathrm{~h}$ after IS,
SBP and DBP were favorable factors strongly predictive of freedom from 90-day MANE. Interestingly, further analysis revealed that the incidence of MANE varied with SBP upon presentation (subgroup (A) $\leq 135 \mathrm{mmHg}$, subgroup (B) $>135 \mathrm{mmHg}$ to $\leq 150 \mathrm{mmHg}$ and subgroup (C) $>150 \mathrm{mmHg})$ were $38.3 \%(n=23 / 60), 17.0 \%(9 / 53)$, and $24.1 \%$ (13/54), respectively. As compared with the other

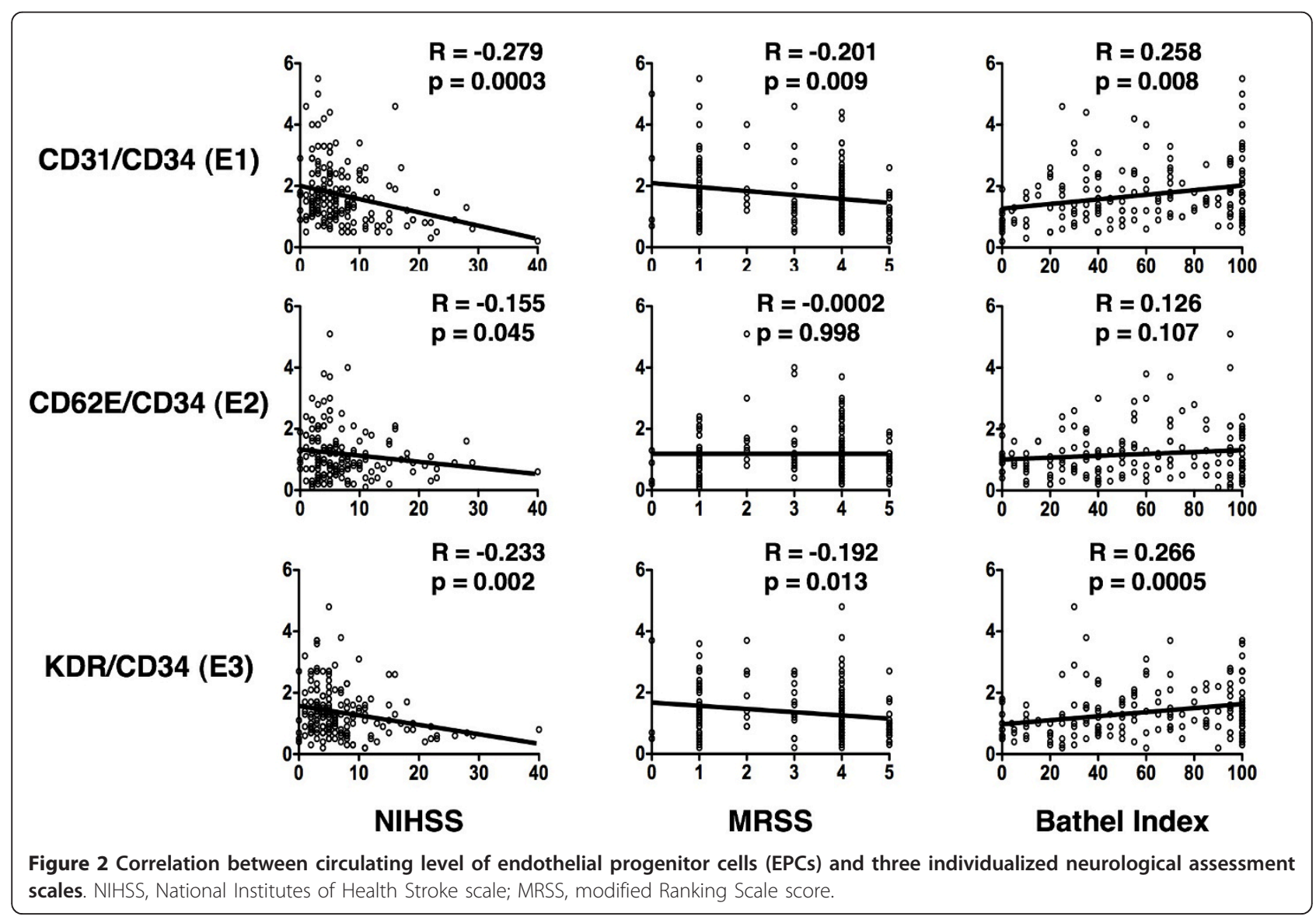


Table 4 Time course of circulating level of EPCs

\begin{tabular}{lllll}
\hline Variables & At $\mathbf{4 8} \mathbf{h}$ & On Day 7 & On Day 21 & $\begin{array}{l}\boldsymbol{P} \text { - } \\
\text { value* }\end{array}$ \\
\hline Circulating EPCS in group 1 & & & & \\
CD31/CD34 (\%) & $1.65 \pm 0.91^{\mathrm{a}}$ & $1.52 \pm 1.06^{\mathrm{a}}$ & $2.28 \pm 1.48^{\mathrm{b}}$ & $<0.0001$ \\
CD62E/CD34 (\%) & $1.21 \pm 0.86^{\mathrm{a}}$ & $1.11 \pm 0.76^{\mathrm{a}}$ & $1.50 \pm 1.13^{\mathrm{b}}$ & 0.0409 \\
KDR/CD34 (\%) & $1.34 \pm 0.76^{\mathrm{a}}$ & $1.16 \pm 0.70^{\mathrm{a}}$ & $1.81 \pm 1.25^{\mathrm{b}}$ & 0.0001 \\
Circulating EPCs in group 2 & & & \\
CD31/CD34 (\%) & $1.75 \pm 1.03$ & $1.48 \pm 0.89$ & $1.64 \pm 0.79$ & 0.071 \\
CD62E/CD34 (\%) & $1.16 \pm 0.76$ & $1.14 \pm 0.75$ & $1.14 \pm 0.72$ & 0.973 \\
KDR/CD34 (\%) & $1.37 \pm 0.89$ & $1.24 \pm 0.80$ & $1.22 \pm 0.72$ & 0.267 \\
\hline
\end{tabular}

*: by repeated measure of ANOVA.

Letters ${ }^{(\mathrm{a}, \mathrm{b}}$ ) indicate significant difference (at 0.05 level) by Tukey multiple comparison procedure.

two subgroups, subgroup (B) was significantly associated with a reduction in 90-day MANE (all $P<0.05$ ).

Multiple stepwise logistic regression analysis demonstrated that total cholesterol level was significantly and independently predictive of 90-day MANE (Table 5). In contrast, SBP, EPO treatment, and circulating $\mathrm{EPC}\left(\mathrm{E}_{3}\right)$ level were significantly and independently predictive of improvement in 90-day MANE.

Univariate and multivariate analyses of predictors for 90 day combined end point (recurrent stroke or death) Univariate analysis of enrollment variables in Tables 1 and 3 demonstrated that serum levels of creatinine were significantly correlated with 90-day combined end point (Table 6). On the other hand, EPO therapy and serum level of HDL were significantly predictive of freedom from a 90-day combined end point. Multiple stepwise logistic regression analysis demonstrated that EPO

Table 5 Logistic regression analysis of predictors for combined MANE on Day 90 after ischemic stroke

\begin{tabular}{llll}
\hline Variables & Odds Ratio & $\mathbf{9 5 \%} \mathbf{C l}$ & $\boldsymbol{P}$-value \\
\hline Univariate & & & \\
Systolic blood pressure* & 0.978 & 0.960 to 0.996 & 0.017 \\
Diastolic blood pressure* $^{*}$ & 0.962 & 0.931 to 0.994 & 0.019 \\
Total cholesterol level & 1.012 & 1.003 to 1.021 & 0.006 \\
Low-density lipoprotein & 1.013 & 1.003 to 1.022 & 0.010 \\
EPO therapy & 0.347 & 0.168 to 0.717 & 0.004 \\
KDR/CD34 & 0.609 & 0.373 to 0.995 & 0.048 \\
Multiple Stepwise & & & \\
Total cholesterol level & 1.012 & 1.003 to 1.021 & 0.010 \\
Systolic blood pressure* & 0.979 & 0.960 to 0.998 & 0.031 \\
KDR/CD34 & 0.583 & 0.341 to 0.997 & 0.049 \\
EPO therapy & 0.334 & 0.153 to 0.730 & 0.006 \\
\hline
\end{tabular}

$\mathrm{Cl}$, confidence interval; EPO, erythropoietin.

MANE, major adverse neurological event (defined as NIHSS $\geq 8$, recurrent stroke or death on day 90 after acute IS); NIHSS, national institutes of health stroke scale.

* Indicates the continuity of systolic and diastolic blood pressure to be used for statistical analysis but not the history of hypertension.
Table 6 Predictors for combined death and recurrent stroke on Day $\mathbf{9 0}$ after ischemic stroke

\begin{tabular}{llll}
\hline Variables & Odds Ratio & $95 \% \mathrm{Cl}$ & $P$-value \\
\hline Univariate & & & \\
$\quad$ High-density lipoprotein & 0.921 & 0.857 to 0.990 & 0.026 \\
$\quad$ EPO therapy & 0.206 & 0.043 to 0.983 & 0.004 \\
$\quad$ Creatinine & 3.250 & 1.045 to 10.109 & 0.042 \\
$\begin{array}{l}\text { Multiple Stepwise } \\
\quad \text { High-density lipoprotein }\end{array}$ & 0.909 & 0.842 to 0.983 & 0.016 \\
$\quad$ EPO therapy & 0.155 & 0.031 to 0.772 & 0.023 \\
\hline
\end{tabular}

$\mathrm{Cl}$, confidence interval; EPO, erythropoietin; MANE, major adverse neurological event.

treatment and serum level of HDL were significant and independent predictors of freedom from 90-day combined end point (Table 6).

\section{Discussion}

This study, which investigated the safety and efficacy of EPO therapy in boosting the circulating level of EPCs and improving 90-day clinical outcome in patients after acute IS, provides some notable information. First, as compared with the healthy controls, circulating levels of EPCs were remarkably increased in patients after acute IS. Our findings are comparable with those of our recent report [24]. Second, there were no serial changes in circulating EPC level after acute IS. Third, only EPO therapy in the acute phase of IS was associated with an increase in circulating levels of EPC at the convalescent phase of IS. Besides, EPO therapy was significantly associated with a reduction in the incidence of recurrent stroke. Fourth in importance was the fact that, in addition to being without side effects, EPO therapy and increased circulating EPC $\left(E_{3}, K D R / C D 34\right)$ were significantly and independently predictive of a decrease in 90-day MANE.

\section{Value and level of circulating EPCs after acute IS}

Abundant data have shown that EPCs in bone marrow microenvironment [30] migrate to circulation in response to ischemia-related organ dysfunction for angiogenesis $[24,31,32]$. The present study that demonstrated a marked increase in circulating EPC levels in patients after acute IS compared with the normal controls, therefore, reinforced the findings of the previous reports $[24,31,32]$.

Unexpectedly, the present study failed in demonstrating a significant fluctuation in the circulating level of EPC in our patients at three phases after acute IS. Interestingly, as compared with both Barthel Index and modified Ranking Scale score, NIHSS showed a notably better correlation with the circulating level of EPCs $\left(E_{1}\right.$ to $\left.E_{3}\right)$ at $48 \mathrm{~h}$ after IS. Of importance is the fact that the circulating levels of EPCs were found to be inversely and 
significantly correlated to the severity of these three neurological scores at $48 \mathrm{~h}$ after acute IS. Our recent study [24] has revealed that a reduced circulating EPC level was significantly related to severe neurological impairment in patients after acute IS. Importantly, an increase in circulating levels of EPCs was found to be independently predictive of an improved 90-day MANE after IS in the current study. Interestingly, previous studies have shown that bone marrow-derived circulating EPCs play an essential role in repairing endothelial injury and participating directly in angiogenesis and vasculogenesis in systemic vascular beds [33,34]. Besides, contribution of EPCs in maintenance and repair of the cerebral vasculature has also been revealed in ischemiarelated cerebrovascular dysfunction [35]. Therefore, our results strengthen the findings of previous studies [33-35]. Taken together, the results of the present study not only corroborate that of our recent report [24], they also encourage the possible use of the level circulating EPCs as a biomarker for risk stratification in patients after acute IS.

\section{Impact of EPO therapy effectively improves 90-day prognostic outcome after IS}

Interestingly, while the neuroprotective mechanisms underlying EPO therapy have been well investigated in experimental studies [36] including the enhancement of mobilization of EPCs to circulation, attenuation of inflammatory response and cellular apoptosis, and reduction in oxidative stress $[24,37-40]$, only a few clinical interventional studies $[19,20,41]$ have been performed to further clarify the validity of this therapeutic option in improving the clinical outcome of patients after acute IS. On top of that, the data of these clinical observational studies $[19,20,41]$ are too inconsistent to reach a significant conclusion. In the current study, we found an association between EPO therapy and reduction of the incidence of 90-day recurrent stroke. The most important finding in the present study is that EPO therapy was an independent predictor of improvement in 90-day MANE and in 90-day combined end point. Therefore, our findings, in addition to strengthening those of previous studies $[19,41]$, highlight the therapeutic potential of EPO in patients after IS who are not suitable candidates for thrombolysis.

Contrary to the findings of our study, the results of one recent clinical trial did not find an additional benefit of EPO in improving clinical outcome of patients with acute IS undergoing tPA therapy as compared with placebo-controls [20]. However, subgroup analysis of the study showed that EPO therapy improved 90-day clinical outcome of the non-tPA patients. Thus, the findings in subgroup analysis of the study [20] support the results of our study. The reason accounting for the partially consistent results between this recent clinical study [20] and ours remain uncertain. However, there are some issues worthy of being addressed regarding that study [20]. First, as compared with the relative low dose of EPO adopted in our study, a very high EPO dosage used in that clinical trial [20] may raise other unidentified confounding effects such as a polycythemia and thrombosis event, thereby influencing patient outcomes. Second, of distinctive particularity was the majority of patients enrolled in that trial [20] were treated by tPA (a violation of their original protocol), which introduced another variable in assessing the benefit of EPO in improving patient outcome after IS, as tPA therapy may induce bleeding complications that outweigh the benefit of EPO treatment $[13,14,20]$.

\section{Other independent predictors of 90-day MANE}

The impact of blood pressure on clinical outcome after acute IS has been extensively investigated [42-44]. Excessive elevation, reduction, and variability in blood pressure have been reported to be independent prognostic predictors for poor clinical outcome after acute IS $[43,44]$. In the current study, another important finding is that SBP was an independent predictor of 90-day MANE. Further analysis demonstrated that SBP $\geq 135$ $\mathrm{mm} \mathrm{Hg}$ and $\leq 150 \mathrm{~mm} \mathrm{Hg}$ were significantly associated with a favorable 90-day clinical outcome. Previous study [41] has also shown that satisfactory control of SBP within 140 to $150 \mathrm{~mm} \mathrm{Hg}$ was the optimal therapy for improving clinical outcome after acute IS. Therefore, our findings corroborated those of previous studies [42-44].

Another notable finding in the current study is that total cholesterol level was also found to be an independent factor for predicting 90-day MANE in the current study. Conversely, HDL was strongly and independently associated with freedom from 90-day combined end point. Hypercholesterolemia and lower level of HDLcholesterol have been identified as important contributing factors to the development of atherosclerosis and acute arterial obstructive syndrome $[45,46]$. Accordingly, our finding re-emphasizes the importance of serum cholesterol and HDL control in patients after acute IS.

\section{Study limitations}

This study has limitations. First, practically, it is impossible to routinely perform intracranial angiographic examination for the acute IS patients. Therefore, the results of our study did not provide information to address the correlation between the circulating level of EPCs and angiogenesis, such as collateral formation in the brain infarct area. Second, because rather restrictive inclusion criteria were designed in the current study, some critical patients were excluded at the initial 
enrollment period. Thus, the 90 -day mortality rate was relatively low in the current study. Therefore, the impact of EPO therapy on 90-day mortality could not be assessed. Finally, although a statistically significant relationship between EPO therapy and a reduction in the incidence of 90-day recurrent stroke was noted in the current investigation, this study did not give cutoff and define positive and negative predictive values as well as provide sensitivities and specificities of EPO on clinical outcome because this study was not actually designed to perform a prognostic study.

\section{Conclusions}

EPO therapy significantly increased circulating EPC levels and was strongly associated with favorable 90-day clinical outcomes after IS. The results of this study, therefore, may encourage the application of EPO treatment in patients unsuitable for thrombolytic therapy after acute IS.

\section{Key messages}

- EPO therapy in acute phase of IS was associated with an increase in circulating levels of EPCs at the convalescent phase of IS.

- EPO therapy was significantly associated with a reduction in the incidence of 90-day recurrent stroke.

- EPO therapy and increased circulating EPC $\left(E_{3}\right)$ levels were significantly and independently predictive of decreased 90-day MANE.

\begin{abstract}
Abbreviations
ACEl: angiotensin converting enzyme inhibitors; ADC: apparent diffusion coefficient; ARB: angiotensin II type I receptor blockers; DBP: diastolic blood pressure; ECCA: extra-cranial carotid artery; EPC: endothelial progenitor cell; EPO: erythropoietin; FITC: fluorescein isothiocyanate; HDL: high-density lipoprotein; IS: ischemic stroke; KDR: kinase insert domain-conjugating receptor; LDL: low-density lipoprotein; MANE: major adverse neurological event; MNC: mononuclear cell; MRI: Magnetic Resonance Imaging; NIHSS: National Institutes of Health Stroke Scale; PBS: phosphate buffered saline; PE: phycoerythrin; RBC: red blood cell; SBP: systolic blood pressure; tPA: tissue plasminogen activator; WBC: white blood cell.
\end{abstract}

\section{Acknowledgements}

This study is supported by a program grant from the National Science Council, Taiwan, Republic of China (grant no. NSC-97-2314-B-182A-090-MY2).

\footnotetext{
Author details

${ }^{1}$ Division of Cardiology, Department of Internal Medicine, Chang Gung Memorial Hospital - Kaohsiung Medical Center, Chang Gung University College of Medicine, 123 Ta-Pei Road, Niaosong District, Kaohsiung City, 833, Taiwan. ${ }^{2}$ Center for Translational Research in Biomedical Sciences, Chang Gung Memorial Hospital - Kaohsiung Medical Center, Chang Gung University College of Medicine, 123 Ta-Pei Road, Niaosong District, Kaohsiung City, 833, Taiwan. ${ }^{3}$ Department of Neurology, Chang Gung Memorial Hospital Kaohsiung Medical Center, Chang Gung University College of Medicine, 123 Ta-Pei Road, Niaosong District, Kaohsiung City, 833, Taiwan. ${ }^{4}$ Division of General Surgery, Department of Surgery, Chang Gung Memorial Hospital Kaohsiung Medical Center, Chang Gung University College of Medicine, 123 Ta-Pei Road, Niaosong District, Kaohsiung City, 833, Taiwan. ${ }^{5}$ Division of
}

Neurosurgery, Department of Surgery, Chang Gung Memorial Hospital Kaohsiung Medical Center, Chang Gung University College of Medicine, 123 Ta-Pei Road, Niaosong District, Kaohsiung City, 833, Taiwan.

\section{Authors' contributions}

HKY and THT designed the experiment, drafted and performed laboratory work. CKS and SL were responsible for the laboratory assay and troubleshooting. HSL, SFC, CMY, TYT and MYL supervised clinical aspects and participated in patient recruitment. CWL and CHL participated in neurological function assessment. WNC and HKY participated in refinement of experiment protocol and coordination and helped in drafting the manuscript. All authors have read and approved the final manuscript.

\section{Competing interests}

The authors declare that they have no competing interests.

Received: 10 November 2010 Revised: 7 January 2011

Accepted: 26 January 2011 Published: 26 January 2011

\section{References}

1. Hankey GJ: Stroke: how large a public health problem, and how can the neurologist help? Arch Neurol 1999, 56:748-754.

2. World Health Organization: World Health Report 1999 - Making a Difference Geneva, Switzerland: World Health Organization; 1999.

3. Association AH: Stroke Statistics Dallas, Dallas, TX: American Heart Association; 2002.

4. Muir KW, Weir CJ, Murray GD, Povey C, Lees KR: Comparison of neurological scales and scoring systems for acute stroke prognosis. Stroke 1996, 27:1817-1820.

5. Adams HP Jr, Bendixen BH, Kappelle L, Biller J, Love BB, Gordon DL, Marsh EE: Classification of subtype of acute ischemic stroke. Definitions for use in a multicenter clinical trial. TOAST. Trial of Org 10172 in Acute Stroke Treatment. Stroke 1993, 24:35-41.

6. Chen ZM, Sandercock P, Pan HC, Counsell C, Collins R, Liu LS, Xie JX, Warlow $C$, Peto R: Indications for early aspirin use in acute ischemic stroke : A combined analysis of 40000 randomized patients from the chinese acute stroke trial and the international stroke trial. On behalf of the CAST and IST collaborative groups. Stroke 2000, 31:1240-1249.

7. Grau AJ, Weimar C, Buggle F, Heinrich A, Goertler M, Neumaier S, Glahn J, Brandt T, Hacke W, Diener HC: Risk factors, outcome, and treatment in subtypes of ischemic stroke: the German stroke data bank. Stroke 2001, 32:2559-2566.

8. Yip HK, Liou CW, Chang HW, Lan MY, Liu JS, Chen MC: Link between platelet activity and outcomes after an ischemic stroke. Cerebrovasc Dis 2005, 20:120-128.

9. Wardlaw JM, Murray V, Berge E, Del Zoppo GJ: Thrombolysis for acute ischaemic stroke. Cochrane Database Syst Rev 2009, CD000213.

10. Wahlgren N, Ahmed N, Davalos A, Ford GA, Grond M, Hacke W, Hennerici MG, Kaste M, Kuelkens S, Larrue V, Lees KR, Roine RO, Soinne L, Toni D, Vanhooren G: Thrombolysis with alteplase for acute ischaemic stroke in the Safe Implementation of Thrombolysis in Stroke-Monitoring Study (SITS-MOST): an observational study. Lancet 2007, 369:275-282.

11. Adams HP Jr, del Zoppo G, Alberts MJ, Bhatt DL, Brass L, Furlan A, Grubb RL, Higashida RT, Jauch EC, Kidwell C, Lyden PD, Morgenstern LB, Qureshi Al, Rosenwasser RH, Scott PA, Wijdicks EF: Guidelines for the early management of adults with ischemic stroke: a guideline from the American Heart Association/American Stroke Association Stroke Council, Clinical Cardiology Council, Cardiovascular Radiology and Intervention Council, and the Atherosclerotic Peripheral Vascular Disease and Quality of Care Outcomes in Research Interdisciplinary Working Groups: the American Academy of Neurology affirms the value of this guideline as an educational tool for neurologists. Stroke 2007, 38:1655-1711.

12. Bravata DM: Intravenous thrombolysis in acute ischaemic stroke: optimising its use in routine clinical practice. CNS Drugs 2005, 19:295-302.

13. Sandercock P, Berge E, Dennis M, Forbes J, Hand P, Kwan J, Lewis S, Lindley R, Neilson A, Wardlaw J: Cost-effectiveness of thrombolysis with recombinant tissue plasminogen activator for acute ischemic stroke assessed by a model based on UK NHS costs. Stroke 2004, 35:1490-1497.

14. Thomalla G, Sobesky J, Kohrmann M, Fiebach JB, Fiehler J, Zaro Weber O, Kruetzelmann A, Kucinski T, Rosenkranz M, Rother J, Schellinger PD: Two tales: hemorrhagic transformation but not parenchymal hemorrhage 
after thrombolysis is related to severity and duration of ischemia: MRI study of acute stroke patients treated with intravenous tissue plasminogen activator within 6 hours. Stroke 2007, 38:313-318.

15. Calvillo L, Latini R, Kajstura J, Leri A, Anversa P, Ghezzi P, Salio M, Cerami A, Brines M: Recombinant human erythropoietin protects the myocardium from ischemia-reperfusion injury and promotes beneficial remodeling. Proc Natl Acad Sci USA 2003, 100:4802-4806.

16. Hirata A, Minamino T, Asanuma H, Fujita M, Wakeno M, Myoishi M, Tsukamoto O, Okada K, Koyama H, Komamura K, Takashima S, Shinozaki Y, Mori H, Shiraga M, Kitakaze M, Hori M: Erythropoietin enhances neovascularization of ischemic myocardium and improves left ventricular dysfunction after myocardial infarction in dogs. J Am Coll Cardiol 2006, 48:176-184.

17. Nakamura R, Takahashi A, Yamada T, Miyai N, Irie H, Kinoshita N, Sawada T, Azuma A, Matsubara H: Erythropoietin in patients with acute coronary syndrome and its cardioprotective action after percutaneous coronary intervention. Circ J 2009, 73:1920-1926.

18. Hasselblatt M, Ehrenreich H, Siren AL: The brain erythropoietin system and its potential for therapeutic exploitation in brain disease. J Neurosurg Anesthesiol 2006, 18:132-138.

19. Tseng MY, Hutchinson PJ, Richards HK, Czosnyka M, Pickard JD, Erber WN, Brown S, Kirkpatrick PJ: Acute systemic erythropoietin therapy to reduce delayed ischemic deficits following aneurysmal subarachnoid hemorrhage: a Phase II randomized, double-blind, placebo-controlled trial. Clinical article. J Neurosurg 2009, 111:171-180.

20. Ehrenreich H, Weissenborn K, Prange H, Schneider D, Weimar C, Wartenberg K, Schellinger PD, Bohn M, Becker H, Wegrzyn M, Jahnig P, Herrmann M, Knauth M, Bahr M, Heide W, Wagner A, Schwab S, Reichmann H, Schwendemann G, Dengler R, Kastrup A, Bartels C: Recombinant human erythropoietin in the treatment of acute ischemic stroke. Stroke 2009, 40:e647-656.

21. van der Meer P, Voors AA, Lipsic E, van Gilst WH, van Veldhuisen DJ: Erythropoietin in cardiovascular diseases. Eur Heart J 2004, 25:285-291.

22. Lipsic E, van der Meer P, Henning RH, Suurmeijer AJ, Boddeus KM, van Veldhuisen DJ, van Gilst WH, Schoemaker RG: Timing of erythropoietin treatment for cardioprotection in ischemia/reperfusion. J Cardiovasc Pharmacol 2004, 44:473-479.

23. Lin JS, Chen YS, Chiang HS, Ma MC: Hypoxic preconditioning protects rat hearts against ischaemia-reperfusion injury: role of erythropoietin on progenitor cell mobilization. J Physiol 2008, 586:5757-5769.

24. Yip HK, Chang LT, Chang WN, Lu CH, Liou CW, Lan MY, Liu JS, Youssef AA, Chang HW: Level and value of circulating endothelial progenitor cells in patients after acute ischemic stroke. Stroke 2008, 39:69-74

25. Goldstein LB, Bertels C, Davis JN: Interrater reliability of the NIH stroke scale. Arch Neurol 1989, 46:660-662.

26. Mahoney Fl, Barthel DW: Functional Evaluation: The Barthel Index. Md State Med J 1965, 14:61-65.

27. van Swieten JC, Koudstaal PJ, Visser MC, Schouten HJ, van Gijn J: Interobserver agreement for the assessment of handicap in stroke patients. Stroke 1988, 19:604-607.

28. Lambiase PD, Edwards RJ, Anthopoulos P, Rahman S, Meng YG, Bucknall CA, Redwood SR, Pearson JD, Marber MS: Circulating humoral factors and endothelial progenitor cells in patients with differing coronary collateral support. Circulation 2004, 109:2986-2992.

29. Rustemeyer P, Wittkowski W, Greve B, Stehling M: Flow-cytometric identification, enumeration, purification, and expansion of CD133+ and VEGF-R2+ endothelial progenitor cells from peripheral blood. J Immunoassay Immunochem 2007, 28:13-23.

30. Asahara T, Masuda H, Takahashi T, Kalka C, Pastore C, Silver M, Kearne M, Magner M, Isner JM: Bone marrow origin of endothelial progenitor cells responsible for postnatal vasculogenesis in physiological and pathological neovascularization. Circ Res 1999, 85:221-228.

31. Wang CH, Verma S, Hsieh IC, Chen YJ, Kuo LT, Yang NI, Wang SY, Wu MY, Hsu CM, Cheng CW, Cherng WJ: Enalapril increases ischemia-induced endothelial progenitor cell mobilization through manipulation of the CD26 system. J Mol Cell Cardiol 2006, 41:34-43.

32. Massa M, Rosti V, Ferrario M, Campanelli R, Ramajoli I, Rosso R, De Ferrari GM, Ferlini M, Goffredo L, Bertoletti A, Klersy C, Pecci A, Moratti R, Tavazzi L: Increased circulating hematopoietic and endothelial progenitor cells in the early phase of acute myocardial infarction. Blood 2005, 105:199-206.
33. Takahashi T, Kalka C, Masuda H, Chen D, Silver M, Kearney M, Magner M, Isner JM, Asahara T: Ischemia- and cytokine-induced mobilization of bone marrow-derived endothelial progenitor cells for neovascularization. Nat Med 1999, 5:434-438.

34. Luttun A, Carmeliet G, Carmeliet P: Vascular progenitors: from biology to treatment. Trends Cardiovasc Med 2002, 12:88-96

35. Taguchi A, Matsuyama T, Moriwaki H, Hayashi T, Hayashida K, Nagatsuka K, Todo K, Mori K, Stern DM, Soma T, Naritomi H: Circulating CD34-positive cells provide an index of cerebrovascular function. Circulation 2004, 109:2972-2975

36. Minnerup J, Heidrich J, Rogalewski A, Schabitz WR, Wellmann J: The efficacy of erythropoietin and its analogues in animal stroke models: a meta-analysis. Stroke 2009, 40:3113-3120.

37. Brines ML, Ghezzi P, Keenan S, Agnello D, de Lanerolle NC, Cerami C, Itri LM, Cerami A: Erythropoietin crosses the blood-brain barrier to protect against experimental brain injury. Proc Natl Acad Sci USA 2000, 97:10526-10531.

38. Villa $\mathrm{P}$, Bigini $\mathrm{P}$, Mennini T, Agnello D, Laragione T, Cagnotto A, Viviani $B$, Marinovich M, Cerami A, Coleman TR, Brines M, Ghezzi P: Erythropoietin selectively attenuates cytokine production and inflammation in cerebral ischemia by targeting neuronal apoptosis. J Exp Med 2003, 198:971-975.

39. Digicaylioglu M, Lipton SA: Erythropoietin-mediated neuroprotection involves cross-talk between Jak2 and NF-kappaB signalling cascades. Nature 2001, 412:641-647.

40. Kawakami M, Sekiguchi M, Sato K, Kozaki S, Takahashi M: Erythropoietin receptor-mediated inhibition of exocytotic glutamate release confers neuroprotection during chemical ischemia. J Biol Chem 2001, 276:39469-39475.

41. Ehrenreich $H$, Hasselblatt M, Dembowski C, Cepek L, Lewczuk P, Stiefel M, Rustenbeck HH, Breiter N, Jacob S, Knerlich F, Bohn M, Poser W, Ruther E, Kochen M, Gefeller O, Gleiter C, Wessel TC, De Ryck M, Itri L, Prange H, Cerami A, Brines M, Siren AL: Erythropoietin therapy for acute stroke is both safe and beneficial. Mol Med 2002, 8:495-505.

42. Spence JD: Treating hypertension in acute ischemic stroke. Hypertension 2009, 54:702-703.

43. Leonardi-Bee J, Bath PM, Phillips SJ, Sandercock PA: Blood pressure and clinical outcomes in the International Stroke Trial. Stroke 2002, 33:1315-1320.

44. Sare GM, Ali M, Shuaib A, Bath PM: Relationship between hyperacute blood pressure and outcome after ischemic stroke: data from the VISTA collaboration. Stroke 2009, 40:2098-2103.

45. Ray KK, Cannon CP, Cairns R, Morrow DA, Ridker PM, Braunwald E: Prognostic utility of apoB/Al, total cholesterol/HDL, non-HDL cholesterol, or hs-CRP as predictors of clinical risk in patients receiving statin therapy after acute coronary syndromes: results from PROVE IT-TIMI 22. Arterioscler Thromb Vasc Biol 2009, 29:424-430.

46. Besler C, Heinrich K, Riwanto M, Luscher TF, Landmesser U: High-density lipoprotein-mediated anti-atherosclerotic and endothelial-protective effects: a potential novel therapeutic target in cardiovascular disease. Curr Pharm Des 2010, 16:1480-1493.

\section{doi:10.1186/cc10002}

Cite this article as: Yip et al.: Effect of erythropoietin on level of circulating endothelial progenitor cells and outcome in patients after acute ischemic stroke. Critical Care 2011 15:R40.

\section{Submit your next manuscript to BioMed Central and take full advantage of:}

- Convenient online submission

- Thorough peer review

- No space constraints or color figure charges

- Immediate publication on acceptance

- Inclusion in PubMed, CAS, Scopus and Google Scholar

- Research which is freely available for redistribution 